\title{
Run up over Breakwaters with different Placement Method of Cube Units
}

\author{
Müge Gülver Gültekin Cihan Gültekin Yalçın Yüksel Esin Çevik
}

\begin{abstract}
The study presents the results of an experimental study of wave run-up over the breakwaters with cube units having different porosity due to different placement method. The cube units were placed by double pyramid method. By using this method two different porosities were obtained. For the first placement the porosity was $33 \%$ and for the second placement the porosity was $43 \%$. The laboratory tests on cube breakwaters exposed irregular waves were studied. The results of the tests showed that the placement configuration of cube units had an important impact on wave run-up.
\end{abstract}

Keywords- breakwater, run-up, cube units, porosity, irregular wave.

\section{Introduction}

Wave run up is generally defined as the upper limit of wave uprush above still water level. If wave run up exceeds the crest height of the structure, wave overtopping occurs.

The wave run up over beaches, coastal structures and breakwaters are very important since population of the world is mostly concentrated near the coastal areas. The prediction of wave run up on coastal structures was of great importance in determining the crest height of the structures. But in recent years wave run-up became less important for rock-armored slopes and rubble mound structures, and the crest height of these types of structures has mostly been based on allowable overtopping. Still an estimation or prediction of wave run-up is valuable as it gives a prediction of the number or percentage of waves which will reach the crest of the structure and eventually give wave overtopping. And this number is needed for a good prediction of individual overtopping volumes per wave, overtopping velocities, and flow depths (Schuttrumpf et al., $* * * *)$.

Wave up-rush and down-rush on the seaward slope of the structure also affect the forces acting on armour units and the stability and movement of armor units (Kobayashi and Otta, 1987).

The aim of the study was to investigate the effect of porosity of double pyramid placement method of cube units on a breakwater on the run up exposed irregular waves.

Müge Gülver Gültekin, Cihan Gültekin

MAG Engineering Services

Turkey

Yalçın Yüksel, Esin Çevik

Yıldız Technical University

Turkey

\section{Experimental Setup and Procedures}

An experimental research was carried out in the wave flume of the Coastal and Harbor Engineering laboratory at Yildiz Technical University. The flume has $26 \mathrm{~m}$ in length, 1 $\mathrm{m}$ in width and $1 \mathrm{~m}$ in depth. The channel is equipped with a displacement piston type wave generator that has an active reflection compensation system.

A cube-block breakwater model for a trunk section was tested for the determination of run up for two different configurations cube units (Fig. 1). The breakwater model was set on a horizontal bottom. The slope of the structure was 1/1.5. The nominal diameter of the cube-blocks in the armour layer was $D_{n}=40 \mathrm{~mm}$. The under layer is consisted of stones with a nominal diameter of $19 \mathrm{~mm}$.

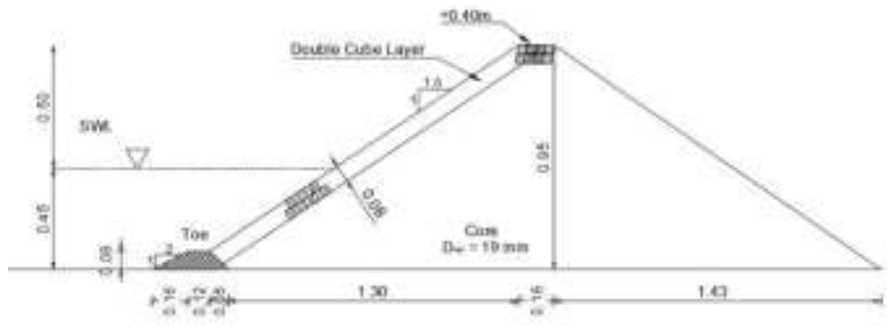

Figure 1. Cross section of the laboratory model

The porosities of the blocks by using double pyramidal placement method were obtained as $33 \%$ and $43 \%$ for the first and second placement methods, respectively (Fig. 2). Water depth was $0.45 \mathrm{~m}$ for all the tests.

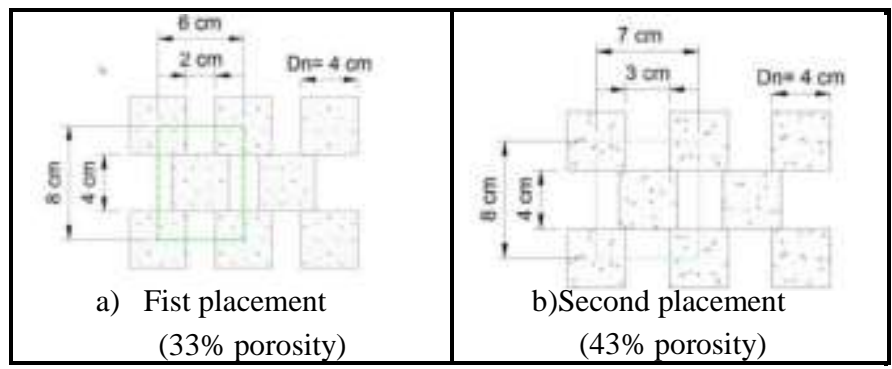

Figure 2. Double pyramid placements for two different packing densities 
A total of 7 irregular wave conditions with JONSWAP spectrum were selected for the tests. The peak-shape parameter of the spectrum was chosen as 3.3 Wave conditions were measured at six different locations. One wave probe was placed in front of the structure toe, one at deep water and four were in constant water depth with known spacing's to determine reflections. Significant wave height and peak wave period in front of the toe are given in Table $1 . \mathrm{H}_{\mathrm{m} 0}$ is the spectral significant wave height in a wave train at the toe of the structure and the peak wave period, $T_{p}$, is the wave period of the highest energy. The analysis of the distribution of the wave energy as a function of wave frequency for a time-series of individual waves is referred to as a spectral analysis. The steepness range of the waves in this study is 0.032-0.049 (calculated with the peak wave periods).

TABLE I. TEST CONDITIONS

\begin{tabular}{|c|c|c|}
\hline Test name & $\begin{array}{c}\text { Significant } \\
\text { wave height, } \\
\text { Hmo (m) }\end{array}$ & $\begin{array}{c}\text { Peak wave } \\
\text { period, } \\
\boldsymbol{T}_{\boldsymbol{p}(\boldsymbol{s})}\end{array}$ \\
\hline W1 & 0.12 & 1.5 \\
\hline W2 & 0.14 & 1.6 \\
\hline W3 & 0.15 & 1.7 \\
\hline W4 & 0.16 & 1.8 \\
\hline W5 & 0.18 & 1.8 \\
\hline W6 & 0.18 & 2 \\
\hline W7 & 0.24 & 1.8 \\
\hline
\end{tabular}

During each test, the storms were recorded by a video camera which is perpendicular to the slope. The run up of each wave of a storm was determined by visualization technique. For irregular waves run up can be defined by different characteristic values such as $\mathrm{Ru} \% 2$ (the value exceeded by $2 \%$ of the run ups), $\mathrm{Ru}_{\mathrm{ave}}$ (average of all run ups), $\mathrm{Ru}_{\max }$ (maximum run up in a storm). Examples for a maximum run up and minimum run up are given in Fig. 3a and b, respectively.

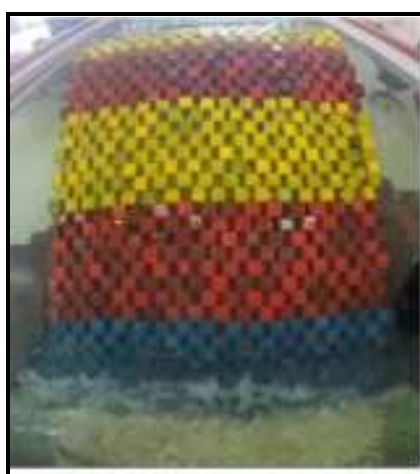

(a)

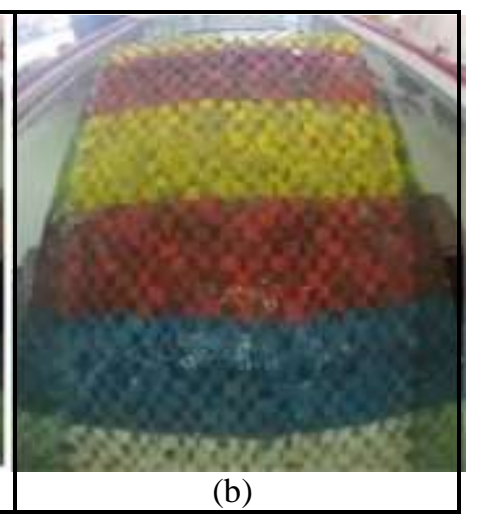

(b)
Figure 3. Views from minimum and maximum run ups

\section{Discussion and Result}

Based on the physical model tests, the effect of placement method on run up of waves over the cube breakwater were investigated in the present study. Fig. 4 shows variation of the normalized average run up with respect to water depth versus normalized wave height for both placement methods. As seen from the figure the wave run up increases with increasing wave height. In addition to this, the run ups for the first placement method are bigger than that of the second placement method for all wave conditions.

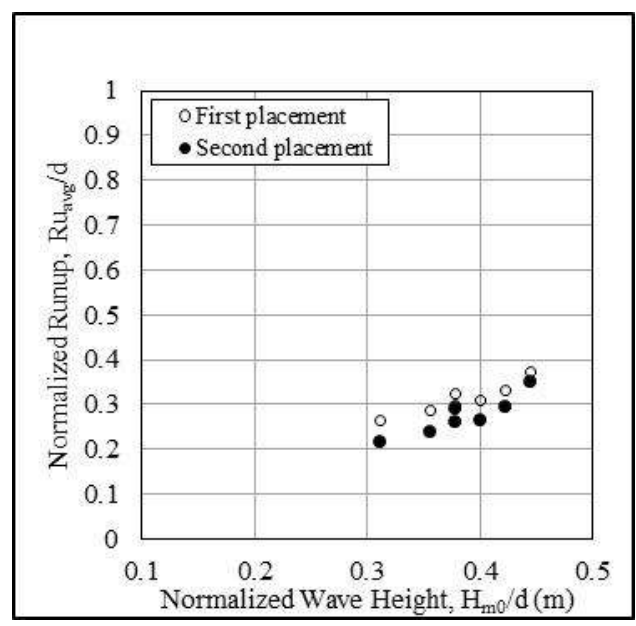

Figure 4. Normalized average run up versus normalized wave height for both placement method

Fig. 5 shows variation of the normalized maximum run up with respect to normalized wave height for both placement methods. Maximum run up height for the first placement method is bigger than that of the second placement method, as well.

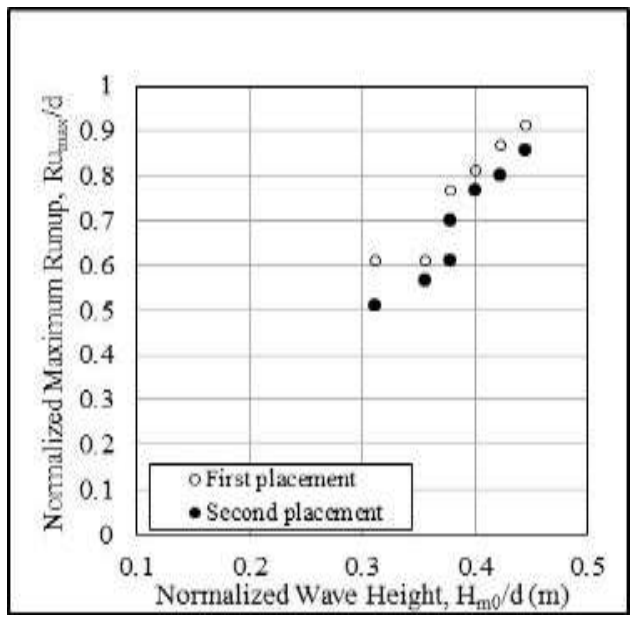

Figure 5. Normalized average run up versus normalized wave height for both placement method

Figs. 6 and 7 show the variation of normalized average and maximum run ups versus normalized wave height for the first and second placement methods, respectively. Although both 
figures show very similar trends, second placement method reduced the run up height relative to first placement method.

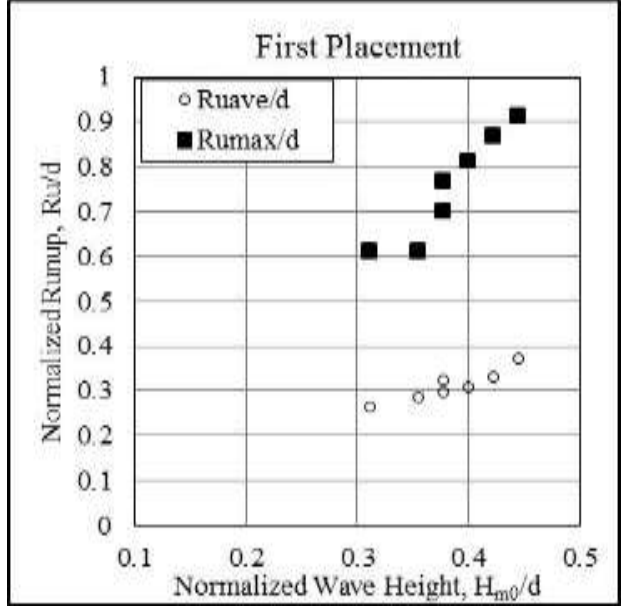

Figure 6. Normalized average and maximum run up versus normalized wave height for the first placement method

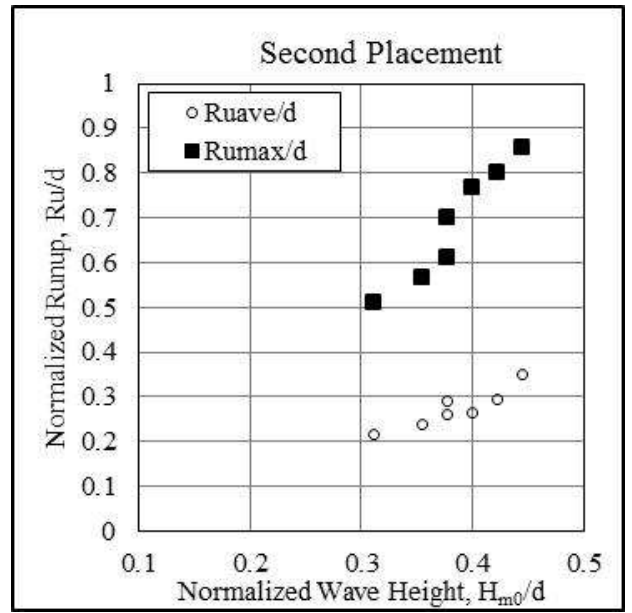

Figure 7. Normalized average and maximum run up versus normalized wave height for the second placement method

\section{Conclusion}

As mentioned before, the main goal of this study was to investigate the effect of placement pattern of cube units of a breakwater on wave run up heights. The results showed that the effect of placement of cube units on run up heights is significant.

- As the porosity increases run up heights decreases.

- The run up increases as the wave height increases.

\section{References}

[1] N. Kobayashi and A.K, Otta, "Hydraulic stability of armour units", J. Waterway, Port, Coastal and Ocean Engineering, ASCE, vol.113(2), pp.171-186, 1987.
[2] J. Van der Meer, A. Kortenhaus, T. Bruce and L. Franco, "Wave Run-Up and Wave Overtopping at Armored Rubble Slopes and Mounds" Handbook of Coastal and Ocean Engineering, World Scientific, 1009. 